\title{
Lower Risk of Home Hemodialysis Attrition in Patients Using Nx2me Connected Health Technology
}

Jose Molina $^{1}$, MBA; Paul Kravitz ${ }^{1}$, BSc; Eric Weinhandl ${ }^{1,2}$, MS, PhD

${ }^{1}$ NxStage Medical, Inc, Lawrence, MA, United States
${ }^{2}$ Department of Pharmaceutical Care and Health Systems, University of Minnesota, Minneapolis, MN, United States

Corresponding Author:

Eric Weinhandl, MS, PhD

NxStage Medical, Inc

350 Merrimack Street

Lawrence, MA, 01843

United States

Phone: 19522888290

Fax: 19786874750

Email: $\underline{\text { eweinhandl@nxstage.com }}$

\begin{abstract}
Background: Home hemodialysis is a growing treatment modality for end-stage renal disease. Home hemodialysis facilitates increased treatment frequency, which may reduce intradialytic symptoms, decrease risk of cardiovascular morbidity, and improve quality of life. However, patients may elect to discontinue home hemodialysis for medical or psychosocial reasons and to convert to in-center hemodialysis. Tools that improve communication and coordination between patients and providers and reduce therapy burden on patients may reduce risk of attrition. Nx2me Connected Health (NxStage Medical, Inc, Lawrence, MA) is a telehealth platform that collects NxStage System One cycler data and patient factors (eg, blood pressure, weight), transmits data to providers after each dialysis session, and enables providers to review data in the Nx2me Clinician Portal regularly; in contrast, usual care involves monthly review of patient-completed session records on paper.
\end{abstract}

Objective: To assess whether use of Nx2me Connected Health was associated with reduced risk of home hemodialysis attrition in patients on the System One cycler.

Methods: We collected data from home hemodialysis patients that initiated use of Nx2me Connected Health. At first use of Nx2me, we identified cumulative time with the System One cycler and treatment setting (in-center training or home). From NxStage records, we identified 3 matched controls for each Nx2me user. Specifically, for a Nx2me user who had accumulated $t$ days with the System One cycler at first use of Nx2me, we identified potential controls who had also accumulated at least t days with the System One cycler (without use of Nx2me) and retained those in the same treatment setting as the Nx2me user at t days after first use of the System One cycler. We randomly selected 3 matched controls from this subset. We followed Nx2me users and matched controls until home hemodialysis attrition and classified the cause of attrition as non-controllable (due to transplant or death) or controllable (due to health issues, therapy burden, or other reasons). We used Fine-Gray competing-risks regression to model incidence of attrition, with stratification by matched cluster and adjustment for race, vascular access modality, and number of dialysis sessions per week.

Results: We identified $401 \mathrm{Nx} 2$ me users (cumulative follow-up years, 356) and 1203 matched controls (1111). Crude attrition rates in Nx2me users and matched controls were 39.6 and 50.6 stops per 100 patient-years, respectively. For Nx2me users versus matched controls, adjusted hazard ratios of attrition due to controllable causes were 0.64 (95\% CI 0.49-0.83) overall and 0.52 (95\% CI 0.36-0.76) in the subset of patients with $<3$ months on the System One cycler at first use of Nx2me (and their respective matched controls). In contrast, adjusted hazard ratios of attrition due to non-controllable causes were 1.09 (95\% CI 0.79-1.51) overall and 1.01 (95\% CI 0.55-1.84) in the aforementioned subset.

Conclusions: Use of $\mathrm{Nx} 2 \mathrm{me}$ Connected Health reduced risk of home hemodialysis attrition due to health issues, therapy burden, and other reasons that ordinarily lead to conversion to in-center hemodialysis. The magnitude of risk reduction was larger in patients who initiated use of Nx2me shortly after first treatment with the NxStage System One cycler.

(iproc 2016;2(1):e15) doi: 10.2196/iproc.6080 


\section{KEYWORDS}

end stage renal disease; home hemodialysis; technique failure; telehealth

This poster was presented at the Connected Health Symposium is displayed as an image in Figure 1 and as a PDF in Multimedia 2016, October 20-21, Boston, MA, United States. The poster Appendix 1.

Figure 1. Poster.

\section{Lower Risk of Home Hemodialysis Attrition}

in Patients Using Nx2me Connected Health Technology

Jose Molina, MBA, ${ }^{1}$ Paul Kravitz, BS, ${ }^{1}$ Eric Weinhandl, PhD, MS 1,2

${ }^{1}$ NxStage Medical, Inc., Lawrence, MA; ${ }^{2}$ Department of Pharmaceutical Care \& Health Systems, University of Minnesota, Minneapolls, MN

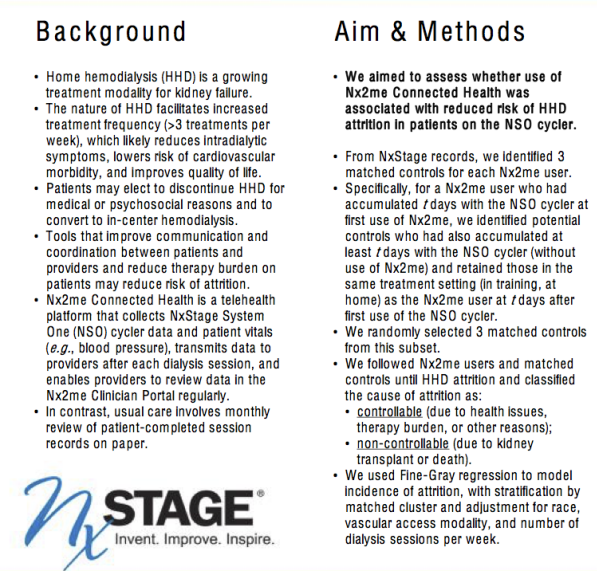

Results

- We Identiffed 401 Nx2me users (356
tollow-up years) and 1203 matched OHow-up years) and 1203 matched - Among Nx2me users: - mean age was 53 years;
roughly 2 in 3 were male;
mean time on the NSO cycler at first use

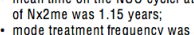
- mode treatment trequency was 5
hemodialysis sessions per week.

- Crude HHD attrition rates in Nx2me users and matched controls were 39.6 and 50.6
events per 100 patient-years, res pectively. - For N×2me users versus matched
controls, the adiusted hazard ratios of

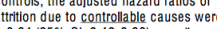
$-0.64(95 \%) \mathrm{Cl}, 0.49-0.83)$ overall;
$.0 .52(95 \%$ CI, $0.36-0.76)$ in the subset
of pattents with $<3$ months on the NSO $-0.52(95 \%) \mathrm{C} 10.36-0.76)$ in the subset
of patents with <3 months on the NSO
cycler at first use of Nx2me. cycler at first use of Nx2me.
- It contrast, the addusted hazard ratios of
atrtition due to non-controllable causes were:
- $1.09(95 \% \mathrm{Cl}, 0.79-1.51)$ overall;

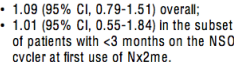

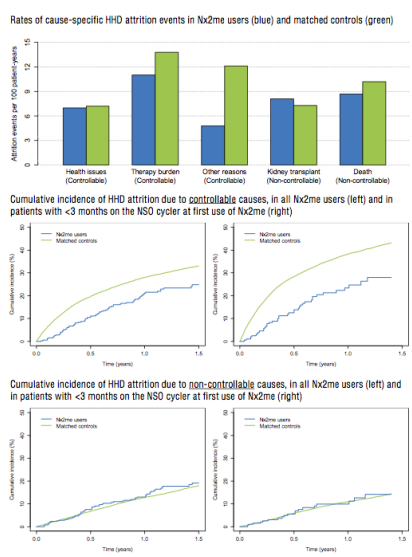

Conclusions

- Use of Nx2me Connected Heath reduced
IIsk of HHD attrition due to controllable causes.
$H H D$ attrition due to controlable causes - HHD atritition due to controlable causes
almost always results in conversion from week) in the home to conventional hemodialysis ( 3 treatments per week) in health care tacility.
Thus, preventing HHD atritition due to
controllable causes keeps patients in controllable causes keeps patients in their
homes and preserves the clinical benefits of increased treatment trequency.

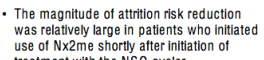
treatment with the NSO cycler.
During the first months of heme the home setting, patients and care Gartners report feeling scared or worrie - Nx2me may serve as a surrogate nurse
and reduce anxiety, thus improving HHD and reduce
persistence.

- Future studles should assess how use of Nx2me alters communnicatlon between
nations

\section{Multimedia Appendix 1}

Poster.

[PDF File (Adobe PDF File), 269KB-Multimedia Appendix 1]

Edited by T Hale; submitted 03.06.16; peer-reviewed by CHS Scientific Program Committee; accepted 02.08.16; published 20.12.16

Please cite as:

Molina J, Kravitz P, Weinhandl E

Lower Risk of Home Hemodialysis Attrition in Patients Using Nx2me Connected Health Technology iproc 2016;2(1):e15

URL: http://www.iproc.org/2016/1/e15/

doi: 10.2196/iproc.6080

PMID:

(CJose Molina, Paul Kravitz, Eric Weinhandl. Originally published in Iproceedings (http://www.iproc.org), 20.12.2016. This is an open-access article distributed under the terms of the Creative Commons Attribution License (http://creativecommons.org/licenses/by/2.0/), which permits unrestricted use, distribution, and reproduction in any medium, provided the original work, first published in Iproceedings, is properly cited. The complete bibliographic information, a link to the original publication on http://www.iproc.org/, as well as this copyright and license information must be included. 